2013-6

\title{
Raman Spectroscopic Analysis of Human Skin Tissue Sections Ex-vivo: Evaluation of the Effects of Tissue Processing and Dewaxing
}

Syed Mehmood Ali

Technological University Dublin

Franck Bonnier

Technological University Dublin, Franck.Bonnier@tudublin.ie

Ali Tfayli

University Paris-Sud

See next page for additional authors

Follow this and additional works at: https://arrow.tudublin.ie/biophonart

Part of the Analytical, Diagnostic and Therapeutic Techniques and Equipment Commons, Biochemistry Commons, Biological and Chemical Physics Commons, Biophysics Commons, Medical Biotechnology Commons, Optics Commons, and the Skin and Connective Tissue Diseases Commons

\section{Recommended Citation}

Bonnier, F. et al (2013) Raman spectroscopic analysis of human skin tissue sections ex-vivo: Evaluation of the effects of tissue processing and dewaxing, Journal of Biomedical Optics, 18, June. doi: 10.1117/

1.JBO.18.6.061202

This Article is brought to you for free and open access by the DIT Biophotonics and Imaging at ARROW@TU Dublin. It has been accepted for inclusion in Articles by an authorized administrator of ARROW@TU Dublin. For more information, please contact arrow.admin@tudublin.ie, aisling.coyne@tudublin.ie,gerard.connolly@tudublin.ie.

Funder: PRTLI Cycle 4 NBIPI

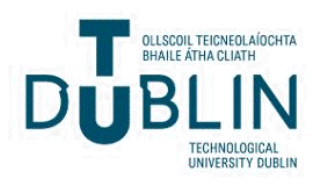




\section{Authors}

Syed Mehmood Ali, Franck Bonnier, Ali Tfayli, Helen Lambkin, Kathleen Flynn, Vincent McDonagh, Claragh Healy, Thomas Lee, Fiona Lyng, and Hugh Byrne 


\title{
Raman spectroscopic analysis of human skin tissue sections $E x$ - vivo: Evaluation of the effects of tissue processing and dewaxing
}

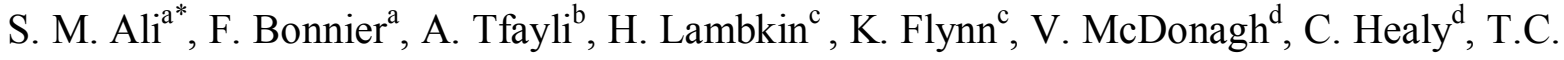 \\ Lee $^{\mathrm{d}}$, F.M. Lyng ${ }^{\mathrm{a}}$, Hugh J. Byrne ${ }^{\mathrm{e}}$ \\ ${ }^{a}$ Radiation and Environmental Science Centre, Focas Research Institute, Dublin Institute of Technology, Kevin Street, \\ Dublin 8, Ireland. \\ ${ }^{\mathrm{b}}$ Univ Paris-Sud, GCAPS "Groupe de Chimie Analytique de Paris-Sud", Faculty of Pharmacy, 92290 Chatenay Malabry, \\ France. \\ ${ }^{\mathrm{c}}$ School of Biological Sciences, Dublin Institute of Technology, Kevin Street, Dublin 8, Ireland. \\ ${ }^{\mathrm{d}}$ Department of Anatomy, Royal College of Surgeons in Ireland, 123 St. Stephen's Green, Dublin 2, Ireland. \\ ${ }^{\mathrm{e}}$ Focas Research Institute, Dublin Institute of Technology, Kevin Street, Dublin 8, Ireland.
}

\begin{abstract}
Raman spectroscopy coupled with K-means clustering analysis (KMCA) is employed to elucidate the biochemical structure of human skin tissue sections, and the effects of tissue processing. Both hand and thigh sections of human cadavers were analysed in their unprocessed and formalin fixed paraffin processed (FFPP) and subsequently dewaxed forms. In unprocessed sections, KMCA reveals clear differentiation of the stratum corneum, intermediate underlying epithelium and dermal layers for sections from both anatomical sites. The stratum corneum is seen to be relatively rich in lipidic content; the spectrum of the subjacent layers is strongly influenced by the presence of melanin, while that of the dermis is dominated by the characteristics of collagen. For a given anatomical site, little difference in layer structure and biochemistry is observed between samples from different cadavers. However, the hand and thigh sections are consistently differentiated for all cadavers, largely based on lipidic profiles. In dewaxed FFPP samples, while the stratum corneum, intermediate and dermal layers are clearly differentiated by KMCA of Raman maps of tissue sections, the lipidic contributions to the spectra are significantly reduced, with the result that respective skin layers from different anatomical sites become indistinguishable. While efficient at
\end{abstract}


removing the fixing wax, the tissue processing also efficiently removes the structurally similar lipidic components of the skin layers. In studies of dermatological processes in which lipids play an important role, such as wound healing, dewaxed samples are therefore not appropriate. Removal of the lipids does however accentuate the spectral features of the cellular and protein components, which may be more appropriate for retrospective analysis of disease progression and biochemical analysis using tissue banks.

\section{Keywords}

Raman Spectroscopy, K-means Cluster Analysis, Human skin tissue, hand, thigh, tissue dewaxing, keratinocytes, melanin, collagen, lipids, wound healing, biochemical analysis

E mail: Mehmood.ali@dit.ie

Ph: +35314027966 


\section{Introduction}

Vibrational spectroscopic techniques, both infrared absorption and Raman scattering, have been widely used for the study of biological samples over the past two decades. The main advantages of these techniques are that they provide a non invasive, label free molecular fingerprint of the tissue and cells. Their potential in medical diagnostics has been well demonstrated and many further reaching applications have been described, including in radiobiology ${ }^{1}$, toxicology ${ }^{2}$ and pharmacokinetics ${ }^{3}$. Coupled with adapted multivariate analysis, the specificity of the information obtained can be used for the identification of different pathologies ${ }^{4,5}$, or variations in metabolism as a result of external agents ${ }^{6,7}$ and even subcellular analysis ${ }^{8,9}$.

In the past, many studies have been carried out using vibrational spectroscopy to classify tissue with a view to cancer diagnosis. Some of the tissue types examined by various groups include cervical ${ }^{10,11}$, lung ${ }^{12,13}$, Brain ${ }^{14}$, oesophagus ${ }^{15-17}$, colon ${ }^{18,19}$, prostate ${ }^{20}$, nasopharynx ${ }^{21}$, larynx ${ }^{22}$, oral ${ }^{23}$, breast ${ }^{24-27}$, liver ${ }^{28}$. In dermatological research, FTIR has been employed for tumour detection in colon and skin biopsies ${ }^{5,29,30}$. Raman spectroscopy has been demonstrated to provide an accurate diagnosis to distinguish basal cell carcinoma from surrounding normal tissue ${ }^{31-33}$ and can also been used as an efficient tool for examination of skin biochemical structure and content ${ }^{34,35}$ of interest for dermal application of cosmetic and pharmacological agents.

A variety of different methods of sample preparation has been employed in these studies; fresh, frozen, air dried, formalin-fixed paraffin-processed (FFPP) and subsequently dewaxed tissue sections. Although considered the gold-standard, fresh or unprocessed skin tissue is difficult to obtain and sectioning can be a delicate task. Embedding in paraffin wax is commonly undertaken to preserve the samples before histological analysis ${ }^{36,37}$ and archived 
embedded tissue banks potentially serve as a significant resource for retrospective prognosis studies.

For clinical relevancy, and indeed acceptance of the techniques by the clinical community, it is important that the sample preparation protocols for Raman spectroscopic analyses are consistent with current practice. The embedding wax itself can, however, contribute significantly to the spectroscopic signature ${ }^{38}$ and although "digital dewaxing" has been demonstrated ${ }^{39}$, it is often important to compare spectroscopic profiling with parallel histological analyses of dewaxed sections. It is critical however to consider the effects of tissue processing on the biochemical integrity of the tissue structures. Cell fixation has been demonstrated to impact on the spectroscopic signatures of cell populations ${ }^{40-42}$ and commonly employed tissue processing techniques have been shown to have similar effects ${ }^{38}$.

In this study, Raman spectroscopy is employed to characterize the biochemical profile of sections of unprocessed human tissue. The layer structure is characterized by comparison to pure biochemical components and keratinocyte cell lines, and the relative morphologies and biochemical content of sections from human hand and thigh are compared. The sections are subsequently dewaxed using standard clinical protocols and the spectral analysis is repeated. It is demonstrated that the tissue processing has significant impact on the extracellular structure, notably the lipidic content, such that tissue sections from different anatomical sites are no longer distinguishable. In the processed tissue sections, however, the decreased lipidic content renders the cellular and extracellular protein structures more distinct, which is potentially advantageous for retrospective analysis of disease progression and biochemical analysis using tissue banks. 


\section{Materials and Methods}

\section{Tissue samples}

Skin tissue was provided through the Anatomical Gift Programme of the Royal College of Surgeons of Ireland (RCSI). Details of the cadaver samples available for this study are provided in Table 1. Skin samples were collected from 11 human cadavers. In each case, both dorsal (back) hand and upper inner thigh sections were employed, and each sample was measured in unprocessed and formalin fixed paraffin embedded (FFPP), and subsequently dewaxed form. All samples are preserved at $-80^{\circ} \mathrm{C}$ before cutting and analysis. Unprocessed cross sections of $20 \mu \mathrm{m}$ thickness were cut with a cryomicrotome (Leica CM $1850 \mathrm{UV}$ ) and were stored at $-20{ }^{\circ} \mathrm{C}$ until used. Spectral profiling of hand and thigh sections, unprocessed and processed, of the samples indicated by shading in Table 1 are presented in detail.

The skin tissue was automatically processed (Leica Histokinette 2000) to wax blocks using four principle steps, as follows:

(i) Vacuum fixation in 10\% buffered formal saline histograde ph 6.8-7.2 (J.T Baker, Deventer, the Netherlands) and heating to $30^{\circ} \mathrm{C}$.

(ii) Vacuum dehydration in industrial methylated spirit IMS T100 (Lennox, Dublin Ireland)

(iii)Vacuum clearing in xylene (Serosep, Limerick, Ireland) and heating to $35^{\circ} \mathrm{C}$.

(iv) Vacuum impregnation with tissue 111 Embedding Wax with polymer added (Sakura, Zoeterwoude, The Netherlands) and heating to $59^{\circ} \mathrm{C}$.

After wax impregnation, tissue was embedded and sliced into $20 \mu \mathrm{m}$ sections using a microtome, mounted on a $\mathrm{CaF}_{2}$ substrate and dried. The samples were immersed in a series of 
baths consisting of two baths of xylene (BDH, Dorest, UK) for five minutes and four minutes respectively, two baths of Ethanol Absolute (Merck, Dorest, UK) for three minutes and two minutes and a final bath of Industrial Methylated spirits 95\% (Lennox Dublin, Ireland) for one minute.

\section{Cell cultures}

HaCaT cells are spontaneously immortalized human epithelial keratinocytes derived from adult skin, and have the characteristics of basal epidermal keratinocytes ${ }^{43}$. This cell line can be used as an in-vitro model for highly proliferative epidermis ${ }^{44}$.

HaCaT cells were cultured in Dulbecco's MEM :F12 (1:1) medium (Sigma, Dorset, UK) containing $10 \%$ fetal calf serum (Gibco, Irvine, UK) 1\% penicillin-streptomycin solution 1000 IU (Gibco, Irvine, UK), 2mM L-glutamine (Gibco, Irvine, UK) and $1 \mu \mathrm{g} \mathrm{mL}^{-1}$ hydrocortisone (Sigma, Dorset, UK) in a humidified atmosphere containing $5 \% \mathrm{CO}_{2}$ at $37{ }^{\circ} \mathrm{C}$. $\mathrm{HaCaT}$ cells were seeded at a concentration of $4 \times 10^{4}$ cells per substrate onto $\mathrm{CaF}_{2}$ substrate (Hellma Ltd., UK), previously sterilised using ethanol then dried in a laminar flow. All samples were incubated for 24 hours at $37^{\circ} \mathrm{C}, 5 \% \mathrm{CO}_{2}$ before measurement. Cells were measured live, in $\mathrm{NaCl}$ solution, using the LUMPlanF1, Olympus immersion objective.

\section{Biochemical compounds}

For comparison to tissue spectra, a number of biochemical compounds were analysed by Raman spectroscopy. The samples were purchased from Sigma-Aldrich (Ireland). Samples of Ceramide, Sphingomyelin and L- $\alpha$-Phosphatidylcholine (1,2-Diacyl-sn-glycero-3phosphocholine, 99\% from egg yolk) were dispersed in chloroform and small amounts of material were drop cast onto $\mathrm{CaF}_{2}$ substrates. 


\section{Raman Instrumentation}

A Horiba Jobin-Yvon LabRAM HR800 spectrometer with an external $300 \mathrm{~mW}$ diode laser operating at $785 \mathrm{~nm}$ as source was used throughout this work. For the measurements, either a x100 objective (MPlanN, Olympus) or a x100 immersion objective (LUMPlanF1, Olympus) was employed, each providing a spatial resolution of $\sim 1 \mu \mathrm{m}$ at the sample. The confocal hole was set at $100 \mu \mathrm{m}$ for all measurements, the specified setting for confocal operation. The system was spectrally calibrated to the $520.7 \mathrm{~cm}^{-1}$ spectral line of silicon and the intensity response function was corrected using the Standard Reference Material (SRM) No. 2243 of the National Institute of Standards, Boulder, Colorado, USA (NIST SRM 2243, 2242, 2241)

45. The Labram system is a confocal spectrometer that contains two interchangeable gratings (300 and 900 lines/mm respectively). In the following experiments, the 300 lines/mm grating was used, giving a spectral dispersion of $\sim 1.5 \mathrm{~cm}^{-1}$ per pixel. The detector used was a 16-bit dynamic range Peltier cooled CCD detector. A step size of $2 \mu \mathrm{m}$ was employed for tissue mapping.

Tissue samples were measured under water immersion to minimise the spectral background and spectra were recorded using the immersion objective (LUMPlanF1, Olympus) ${ }^{46}$. All biochemical samples were recorded using the x100 objective (MPlanN, Olympus). Once all spectra were acquired, a background of substrate measured under identical conditions was subtracted. Minimal baseline correction, smoothing and normalization were also performed in order to improve the quality of the acquired spectra.

\section{Data analysis}

The different data analysis steps were performed using Matlab (Mathworks, USA). Before statistical analysis, a Savitsky-Golay filter $\left(5^{\text {th }}\right.$ order, 7 point $)$ was applied to smooth any spurious peaks of the spectra and reference constituting the background signal. 
K-means cluster analysis (KMCA) was employed to analyse the spectral variations in tissue. It is one of the simplest unsupervised learning algorithms that solves the well known clustering problem and is often used for spectral image analysis ${ }^{19}$. In general, clustering is the partitioning of a data set into subsets (clusters) so that the differences between the data within each cluster are minimized and the differences between clusters are maximized according to some defined distance measure. Using KMCA, the large amount of data in a spectral map can be reduced to mean spectra and the spatial distribution can easily be visualised. The Raman data was used as inputs for KMCA. The clustering analysis algorithm was used to find groups of spectra with similar spectral characteristics (clusters), each one representing regions of the image with similar biochemical profiles. After KMCA, a different colour is assigned to each cluster. Each grid element of the spectral map is then assigned the colour of the particular cluster to which its spectrum belongs. In this way, a pseudo-colour image of the skin sections is created to visualise the organisation of the clusters in the original image. As the tissue mapping step size was $2 \mu \mathrm{m}$ for all measurements, pixel size in the KMCA maps is $2 \mu \mathrm{m} \times 2 \mu \mathrm{m}$. The data range for all KMCA was limited to the fingerprint region, $400 \mathrm{~cm}^{-1}$ to $1800 \mathrm{~cm}^{-1}$.

\section{Results and discussion}

\section{Identification of the different skin layers in unprocessed samples}

Figure 1-I shows a optical microscopic image of a $20 \mu \mathrm{m}$ thick unprocessed hand section of sample $n^{\circ} 3$. Visually, three different regions are apparent. Raman and FTIR spectroscopy, coupled with KMCA can be used for the identification of different structures and classification of tumoral regions in tissue sections ${ }^{29,47}$. It may therefore be anticipated that 
distinct biochemical regions within the skin section can be identified. The maximum biochemical information is contained within the so-called fingerprint region of the spectrum $\left(400-1800 \mathrm{~cm}^{-1}\right)$ and therefore this region was initially analysed. In an automated spectral map of the tissue sections, the spectra recorded on the edge of the tissue exhibit a high degree of variability due to the transition from the outer layer of tissue to the substrate. The variability between these spectra can interfere with the clustering analysis, resulting in the creation of distinct clusters. Best visualization and reproducibility of the different structures existing within the tissue was achieved by setting the number of clusters to 5 . In this way, the variability in the spectra obtained at the edge of the tissue is contained in distinct clusters and does not interfere with the identification of different structures present in the tissue. The spectra were assigned to the 5 different groups according to their similarities and a colour attributed to each cluster. False colour maps were constructed representing the partition of the different clusters in the tissue. The resulting image can be seen in figures 1-II.

Three different structural layers can be found in the skin: the epidermis, the dermis and hypodermis. The latter is too deep to be sampled in vivo using Raman microscopy and is not examined in this study. The epidermis forms the protective layer against the surrounding environment. The dermis provides a structural support to the skin and the hypodermis is a connective tissue layer where fat is stored. The epidermis can also be subdivided into four different layers, starting with the stratum basale, adjacent to the dermis, containing mainly keratinocytes but also melanocytes responsible for the production of melanin, a pigment which protects against UV radiation. The second layer is called the stratum spinosum and is formed from dividing basale cells migrating towards the surface of the skin. The third layer is named the stratum granulosum and is characterised by anuclear cells. As a natural process of maturation, the cells flatten and lose their nucleus. Finally, in contact with the exterior environment, is the stratum corneum. The cells have reached the last stage of their maturation 
and are described as non-viable cornified cells, called corneocytes. A fifth layer, the stratum lucidum, is found is the sole of the foot and palm of the hand and is therefore not present in our samples.

Three different regions of skin can be well differentiated spectroscopically and figures 1-III shows KMCA mean spectra related to the three regions of unprocessed hand derived from the subsection of figure 1-I (indicated by the white rectangle). Of the other two clusters identified, the black (cluster 5) corresponds to the substrate, while the light blue (cluster 4) in figure 1-II is not associated to specific skin structure and represent either a loss of layer integrity during the sectioning process or presence of debris on the substrate. Nevertheless, the specificity of the information contained in the spectra recorded allows discrimination of different skin layers using KMCA. A nalysis of a thigh tissue section yields similar results, as shown in figure 1-IV/1-V/1-VI. Notably, in both cases, the number of layers found is less than that of the skin anatomy described above. It is thus of interest to analyse the spectral features which differentiate these layers of skin, as well as skin from different anatomical sites and elucidate the biochemical origin of their differentiation.

\section{Characterisation of the dermis layer}

Figure 2-I presents a comparison between the KMCA cluster 3 mean spectra for unprocessed hand and the equivalent cluster for thigh (figures 2-I A and B) with pure collagen (figure 2-I C). It can be easily seen that the spectrum of the skin layer is dominated by collagen and it is therefore identified as the dermis. This is due to the high composition of collagen in human dermis, constituting about $70 \%$ of the dry weight and $90 \%$ of the total protein content. There are about 20 types of collagen that exist in the body, but $80 \%$ of skin collagen is type 1 and $15 \%$ is type 3 . The remaining $5 \%$ is thought to be predominately type IV collagen ${ }^{48-50}$. 
Assignments of most Raman bands of collagen have been made by Frushour and Koenig ${ }^{51}$. Specific features in the collagen spectrum are two intense bands at $\sim 855 \mathrm{~cm}^{-1}$ and $\sim 938 \mathrm{~cm}^{-1}$. These bands originate from the amino acid side chain vibrations of proline and hydroproline as well as from a C-C stretching vibration of the collagen backbone. Proline and hydroxyproline make up about one-fourth of the amino acids in collagen, a higher proportion than in most other proteins ${ }^{48}$. More generic protein bands present in the spectrum of the collagen and the dermis appear at $1452 \mathrm{~cm}^{-1}, 1104 \mathrm{~cm}^{-1}$ due to $\mathrm{CH}$ deformation and $\mathrm{C}-\mathrm{N}$ stretching, while features at $1004 \mathrm{~cm}^{-1}$ and $1032 \mathrm{~cm}^{-1}$ are due to symmetric ring breathing and

$\mathrm{CH}$ in-plane bending (Phenylalanine) ${ }^{52-56}$. These bands are also evident in the mean spectra of the other layers, but the collagen specific peaks are absent and they are thus distinctive signatures of the dermal layer.

\section{Characterisation of the epidermal layers}

Overlaying the dermis, although the anatomy of the epidermis divides it into 4 distinct layers, KMCA of the Raman maps identifies only 2 layers. Analysis of the spectral information elucidates the origin of the sub classification.

Figure 2-II displays a comparison between the KMCA cluster 2 mean spectrum of unprocessed hand (A) and the equivalent mean spectrum of unprocessed thigh (B) skin section corresponding to the intermediate epidermal layer with the spectrum of pure melanin (C). The pure melanin spectrum (figure 2-II C) is dominated by the broad fluorescence emission spectrum and no prominent Raman peaks are apparent. The spectra of the intermediate layers of unprocessed hand and thigh skin (figures 2-II-A and 2-II-B) are a superposition of the fluorescence spectrum of melanin itself and the spectrum of the extracellular matrix present in the dermis of the skin. The basal layer of the epidermis is 
primarily composed of melanocytes, which are responsible for the production of melanin. Melanin is one of the most ubiquitous and biologically important pigments in the human body ${ }^{57}$. Although the melanin is produced by melanocytes, the pigment accumulates in melanosomes which are transferred to the adjacent keratinocytes where they remain as granules. Thus, the melanin is distributed beyond the basal layer and can be found in the entire malpighian layer, a term that can be used to collectively describe the stratum spinosum and granulosum ${ }^{58,59}$. The organisation and distribution of the melanin vary between individuals and in darkly pigmented skin, even the corneocytes can contain specks of melanin also described as "dust". However the number of melanocytes is relatively constant ${ }^{57}$.

Because of this pigmented nature, the cluster spectra show a strong background, potentially due to the fluorescence of the melanin, which is resonant at $785 \mathrm{~nm}{ }^{60}$, although distinct Raman peaks can be clearly identified. As a result, the intensity of the spectrum is also exceptionally high. The presence of a strong background in the spectra does not allow to specifically discriminate the basal layer from the malpighian layer and KMCA of the Raman map identifies the combination as an intermediate epithelial layer. An increase in the cluster number to 7 or 10 differentiates more "outlier" regions associated with the interface between sample and substrate, indicating that the variations in this region are larger than those in the intermediate layer, dominated by the melanin fluorescence. The strong background to the Raman spectrum makes it difficult to quantify the melanin levels based on Raman spectroscopy. Moreover, these layers, being mostly composed of keratinocytes, albeit at different stages of maturation, are more likely to be spectroscopically very similar.

Most of the Raman bands in the KMCA spectrum of cluster 1 for unprocessed hand and the equivalent cluster for thigh sections are in agreement with results obtained from FT-Raman measurements on isolated stratum corneum ${ }^{61-64}$. The stratum corneum spectra are dominated by contributions from keratin and lipids. Figure 2-III represents a comparison between the 
Raman spectra of the KMCA cluster 1 for unprocessed hand (A) and the equivalent cluster for unprocessed thigh (B) with spectra of the pure lipids ceramide (C), sphingomyelin (D) and L- $\alpha$-Phosphatidylcholine (E). The position of the amide I band at $1655 \mathrm{~cm}^{-1}$ indicates that keratin in the human stratum corneum adopts predominantly and $\alpha$-helical conformation ${ }^{65,66}$. Additionally, the spectra of cluster 1 hand and the equivalent for thigh have prominent contributions of lipids, observed at $1064 \mathrm{~cm}^{-1}, 1085 \mathrm{~cm}^{-1}$ and $1130 \mathrm{~cm}^{-1}$ due to chain C-C stretching, $1296 \mathrm{~cm}^{-1}$ and $1302 \mathrm{~cm}^{-1}$ due to $\mathrm{CH}_{2}$ twisting, as well as $1446 \mathrm{~cm}^{-1}$ and $1442 \mathrm{~cm}^{-1}$ due to $\mathrm{CH}$ scissoring. All bands can be compared to strong features in the Raman spectra of ceramide, sphingomyelin or phosphatidylcholine. However, the most abundant classes of lipids present in the stratum corneum are ceramide, cholesterol and fatty acids, wherein they play a pivotal role in the skin barrier function. The absence of the intense Raman features at $717 \mathrm{~cm}^{-1}, 1157 \mathrm{~cm}^{-1}$ and $1526 \mathrm{~cm}^{-1}$ clearly highlights that sphingomyelin is absent from the stratum corneum. Similarly, the absence of a strong peak at $717 \mathrm{~cm}^{-1}$ in the spectrum of the skin seems to indicate that no contribution from the phospholipids can be observed. However the presence of a small feature at $1747 \mathrm{~cm}^{-1}$ remains identifiable. The exact lipidic composition of the stratum corneum remains difficult to evaluate. The presence of sebaceous lipids, composed of squalene, wax esters, and triglycerides, coating the skin surface can be a result of contamination during sample preparation ${ }^{67}$. However, in recent studies, the stratum corneum is commonly described as mostly composed of ceramides, fatty acids and cholesterol although other lipids may be present in small quantities. Earlier studies indicated that phospholipids in the stratum corneum account for about $5 \%$ of the total lipids from samples taken from the legs or abdomen but smaller proportions in other location such as the face ${ }^{68,69}, 70$.

The absence of characteristics features of carotenoids in the stratum corneum is also notable. The distribution of these powerful antioxidants in the skin was recently investigated in-vivo 
using Raman microscopy based on the prominent Raman line at $1525 \mathrm{~cm}-1 \quad(\mathrm{C}=\mathrm{C}$ vibration). ${ }^{71-73}$ It is assumed that they are degraded due to the oxidative stress induced by death.

Raman spectroscopy, coupled with KMCA, is clearly a powerful tool to differentiate the layers of skin, as well as layers from different anatomical sites, based on biochemical content. The images reveal significant differences between the morphology and thickness of the stratum corneum and basal layer of the two different anatomical sites. Using the false colour images reconstructed from the $\mathrm{KMCA}$, the dermis can be easily differentiated due to the high content of collagen, and therefore the delimitation between the dermis and the epidermis is easily discernable. The two remaining clusters are attributed to the stratum corneum and an intermediate combination of the basal and malpighian layers. Across the sections of unprocessed hand examined, the total thickness of the epidermis appears to be about $70 \pm 15$ $\mu \mathrm{m}$ whereas in the thigh sections it is within the range $35 \pm 5 \mu \mathrm{m}$. Although the thicknesses vary somewhat from sample to sample, these differences between sections of hand and thigh are consistent across samples from all 11 cadavers measured. The cluster identified as the top layer of the skin without any features of the melanin can be attributed to the stratum corneum, and was found to be respectively $40 \pm 10 \mu \mathrm{m}$ for the unprocessed hand and $25 \pm 5 \mu \mathrm{m}$ for the thigh.

Epidermal thickness is of considerable significance in dermatological research and a considerable amount of work has been done and reported, both in vivo ${ }^{74,75}$ and ex vivo from biopsy samples ${ }^{76-78}$, defining the variations of epidermal thickness of different anatomical sites. The observations here are consistent with those expected for primarily sun-exposed sites (hand) and sun-protected sites (thigh). It has also been observed that the degree of variability on normally clothed body sites is less than that on the normally unclothed sites ${ }^{79}$. Variations in normal skin related to age and gender have also been reported ${ }^{77}$. Published 
values of the thickness of the viable layer (basal layer) and the stratum corneum have been variable. Moreover, the thickness of stratum corneum and other layers of the epidermis are known to be different from different anatomical sites. In recent studies, the total thickness has been found to be between $60 \mu \mathrm{m}$ and $100 \mu \mathrm{m}$ depending on the body sites considered, but more importantly the techniques employed for the measurements ${ }^{80,81}$. However, less is known about the biochemical differences, and Raman spectroscopic analysis can potentially shed further light on chemical differences between the skin layers, and between layers from different anatomical sites. Important for generalisation of deductions is the consistency of the differentiation between specimens. Figures 3-I and 3-II compare the average spectra of the epidermis of unprocessed hand and thigh sections from different anatomical sites. The results are representative of all 11 cadaver measured samples.

The samples available for this study have been taken post-mortem from patients over 80 years (Table 1). The thickness of the different skin layers can be affected by aging or sun exposure and therefore can vary significantly from individual to individual. The observations made can thus not be considered to be representative of the whole population. However, as the samples have been taken from different locations (hand and thigh) for each cadaver, direct comparison between two samples from the same patient remains relevant.

Spectra of the stratum corneum and dermis of different individuals show strong similarities, but some structural and conformational differences are apparent, as illustrated in figures 3-I and 3-II. Overall, the Raman signatures vary significantly and consistently according to body site (hand and thigh). Apparent shifts in the features at 1446/1442 $\mathrm{cm}^{-1}$ and $1296 / 1302 \mathrm{~cm}^{-1}$ are consistently observed from thigh to hand stratum corneum (figure 3). The relative intensity of the signal at $1296 \mathrm{~cm}^{-1}$ and $1302 \mathrm{~cm}^{-1}$ with respect to the peak at $1266 \mathrm{~cm}^{-1}$ also varies. Similar differences are observed between unprocessed hand and thigh sections in the 
case of the intermediate epithelial layer (figure 2-II) and the dermis (figure 3-II). The band located at $1302 \mathrm{~cm}^{-1}$ in thigh dermis (figure 3-II) is assigned to $\mathrm{CH}_{2}$ twisting and this is absent in hand dermis, while the Amide III band located at $1246 \mathrm{~cm}^{-1}$ in hand dermis is absent in thigh dermis. Figure 3 illustrates that these are regions of strong lipid contributions, however, and so, rather than spectral shifts, these characteristic differences are more likely due to differing contributions of lipids to the spectra relative to those of proteins.

Thigh stratum corneum and dermis also display a small peak at $1747 \mathrm{~cm}^{-1}$, which is absent from hand stratum corneum and dermis. This peak is evident in the spectrum of L- $\alpha-$ Phosphatidylcholine (figure 2-III-E) and derives from the $\mathrm{C}=\mathrm{O}$ ester vibration, also present in triglycerides, which are not normally present in the stratum corneum. Triglycerides are esters derived from glycerol and three fatty acids, and their prominence in the thigh tissue may be evidence of higher levels of lipids and fatty acids.

\section{Study of the CH region}

Differences in lipidic content of the different layers can be more clearly visualised in the high wavenumber region of the Raman spectrum, in which the $\mathrm{CH}$ vibrations of the aliphatic chains feature strongly. Figure 4 presents a comparison between the average, baseline corrected, Raman spectra of unprocessed stratum corneum (A), unprocessed intermediate layer (B) unprocessed dermis (C) in the region from $\sim 2700 \mathrm{~cm}^{-1}$ to $\sim 3200 \mathrm{~cm}^{-1}$, compared with

pure ceramide (D) sphingomyline (E) and L- $\alpha$ - phosphatidylcholine (F). The strong contributions of the lipids can be seen clearly in the spectra of all three layers of the frozen skin section, although their relative contributions vary. The spectra can be fitted with individual Gaussian/Lorentzian bands, and the results are summarised in table 2. Spectral positions of the fitted peaks vary somewhat from spectrum to spectrum, and so are quoted 
$\pm 3 \mathrm{~cm}^{-1}$. Fitted peak intensities are reproducible within $10 \%$ and are normalised to the band at $\sim 2932 \mathrm{~cm}^{-1}$. The peaks in the high number region predominantly originate from $\mathrm{CH}, \mathrm{CH}_{2}$ and $\mathrm{CH}_{3}$ stretching, and from literature, many can be assigned to lipids, the remainder being assigned to proteins $34,35,82,83$.

In general, the stratum corneum is seen to be relatively rich in lipidic content, essential for the barrier function of the skin against external agents. The stratum corneum is made up of keratinized cells that are embedded in lipid matrices like bricks in mortar ${ }^{84}$, or more specifically corneocyte cells surrounded by a three dimensional multi lamellar lipid domain 85, 86. As part of the cell maturation the keratinocytes, enzymes degrade the cellular viable components such as nucleus and other organelles. Therefore, corneocytes are anucleated cells, and no DNA or histones should be found in this layer of the skin. The major lipid components of the stratum corneum are ceramides (sphingosines and phytosphingosines), long-chain free fatty acids, and cholesterol ${ }^{87-90}$.

The main lipids in the basal layer are phospholipids, cholesterol and to a lesser extent triglycerides, which provide energy for metabolism. The lipids are subject to maturation and it starts with the apparition of lamellar bodies in the stratum spinosum which contain phospholipids, sphingolipids and cholesterol ${ }^{91}$. The lamellar granules present in the stratum granulosum are particularly rich in glucosylceramides. These granules are released in the intercellular space of the stratum corneum where they will be converted into ceramides via hydrolysis by beta (b)-glucocerebrosidase ${ }^{92,93}$.

Overall, it can be deduced that that lipid/ protein compositions are not uniform in the layers of hand and thigh of the same human cadavers. The sun exposed hand skin is relatively low in lipidic content compared to the thigh. This is consistent with reports that a decrease in lipid content is associated with increased susceptibility to exogenous insults, which will naturally increase with age ${ }^{94}$. The observations may provide unique advantages in skin disease 
diagnosis and this body-site difference needs to be factored into in vivo skin Raman assessment and disease diagnosis. However, it is noted that for both anatomical sites, the Raman spectra of the stratum corneum and dermis of skin sections are strongly influenced by the lipidic and extracellular protein content, rather than the cellular features, which may provide the most direct biochemical information on tissue pathology. Raman spectroscopy can be used, not only to elucidate the structure of the lipids involved in the stratum corneum barrier function (ceramides, cholesterol and free fatty acids), but also to provide a direct insight on the conformational order and the lateral packing of these lipids. It has been shown that the barrier function is directly related to the compactness of the lipid structure and that the later can be affected by external insults such as UV radiation. ${ }^{35,95-97}$

\section{Comparison with processed FFPP sections}

For histological analysis, tissue samples are commonly preserved in paraffin wax 36,37 . Paraffin embedding facilitates tissue cutting, but also is commonly employed, worldwide, for archiving tissue samples. The availability of a wide range of pathologically characterized samples for study potentially enables extensive retrospective studies using spectroscopic and other techniques. However, the paraffin wax itself gives rise to strong Raman signals that overlap the molecular vibrations of the biomolecules of the samples, necessitating chemical removal for spectral analysis ${ }^{38}$. Although it has been demonstrated that the contributions can be removed digitally ${ }^{98}$, histological staining, considered a gold standard, necessitates chemical removal of the wax and thus the procedure is employed here. Furthermore, although it has been demonstrated that dewaxing using hexane is more efficient than the commonly employed xylene, xylene is used here for consistency with clinical protocols ${ }^{38}$.

Figure 5-I shows an optical microscopic image of the dewaxed hand section of human skin of $20 \mu \mathrm{m}$ thickness. As for the unprocessed sections, three different regions are visually 
apparent, the dermis at the bottom and the stratum corneum at the top, separated by an intermediate underlying epidermal layer. In contrast, the optical images of dewaxed hand and thigh skin sections in figures 5-I and 5-IV indicates no major differences between the thicknesses of the total epidermis, which are $\sim 40 \mu \mathrm{m}$ in both thigh and hand. The stratum corneum also appears to have similar thicknesses in both locations, $\sim 20 \mu \mathrm{m}$, despite the large differences observable in the unprocessed sections from the same cadavers. Through the processes of formalin fixation, paraffin embedding and dewaxing, as well as cutting, the tissue sections likely undergo a considerable degree of chemical and physical changes, and it is important to consider the effects of the processing on the biochemical content and structure of the skin layers.

Spectroscopically, the three regions of the sections are quite distinguishable, as illustrated by the KMCA mean spectra of figure 5-III, taken within the subsection of figure 5-I indicated by the white rectangle. The KMCA map of figure 5-II further supports classification of dermis, basal/malpighian layer and stratum corneum. The mean spectra of the principle regions are plotted in figure 5-III. The mean spectrum of cluster 4 is similar to that of cluster 1 . Similar results are observed for dewaxed thigh tissue sections and are shown in figure 5-IV/5-V/5-VI. For both anatomical sites, at first glance, the mean spectra of the 3 identified regions are similar to the corresponding regions for the unprocessed skin sections, but closer examination reveals important differences.

Figure 6-I presents a comparison between the spectra of KMCA cluster 1 of dewaxed skin hand stratum corneum (A) and the equivalent cluster of dewaxed thigh stratum corneum (B) with that of the HaCaT cell line (C), DNA (D), histone (D) and pure paraffin wax (F). Firstly, it is noted that the KMCA spectra of dewaxed epidermis of hand and thigh reveal little or no contributions from the paraffin wax, indicating that the dewaxing procedure has been effective. The characteristic bands of wax (figure 6-I-F) at $1062 \mathrm{~cm}^{-1}, 1131 \mathrm{~cm}^{-1}, 1296 \mathrm{~cm}^{-1}$ and $1441 \mathrm{~cm}^{-1}$, are completely absent 
in the mean spectra of the epidermis of the dewaxed skin hand and thigh (figure 6-I-A and 6I-B). Hence, the wax contribution of the epidermis has been completely removed by the dewaxing procedure. Notably, however, the mean spectra of dewaxed hand and thigh dermis are devoid of lipidic contributions. Both paraffin wax and biological lipids are long chain aliphatic molecules. The spectra of wax and pure lipids show remarkable resemblances (figure 6-I-F-, figure 2-III-C, D, E). The Raman contributions of pure lipids at $1064 \mathrm{~cm}^{-1}$, $1296 \mathrm{~cm}^{-1}$ and $1442 \mathrm{~cm}^{-1}$ in cluster 1 of unprocessed skin hand and thigh (figure 2-I-A and 2I-B) are almost identical to those of pure wax in the wavenumber region of $1000 \mathrm{~cm}^{-1}$ to 1700 $\mathrm{cm}^{-1}$. The results indicate, therefore, that while the dewaxing procedure is successful in completely removing the wax in the tissue, due to the molecular similarity, the process is also effective in the complete removal of the naturally occurring tissue lipids.

Despite minor differences, the spectra of the clusters corresponding to the dewaxed stratum corneum of hand and thigh (figure 6-I-A and 6-I-B) show remarkable resemblances. Proteins bands, such as those at $1450 \mathrm{~cm}^{-1}$ and $1340 \mathrm{~cm}^{-1}$ due to protein $\mathrm{CH}$ deformation, $1255 \mathrm{~cm}^{-1}$ to protein Amide III and $756 \mathrm{~cm}^{-1}$ due to tryptophan ring breathing modes are also present in the spectra of HaCaT cells (figure 6-I-C). Notably, however, the signature bands of nucleic acids, visible in the spectrum of the $\mathrm{HaCaT}$ cells at $785 \mathrm{~cm}^{-1}$ and $1580 \mathrm{~cm}^{-1}$, are absent in the mean spectrum of the stratum corneum.

Although the stratum corneum is rich in lipidic components, after dewaxing it clear that most of the lipids have been lost and the main molecules contributing in the spectra recorded are the proteins, contained within the corneocytes. Although the lipids of the stratum corneum are widely investigated and often considered as the most important component of the skin, the proteins are also subject to a certain degree of reorganisation during the maturation of the keratinocytes from the deepest layers until they reach the surface of the skin. The large insoluble protein named profilaggrin will be converted to filaggrin which is associated to the 
keratin filament in the deepest layers of the stratum corneum. The proteolysis of filaggrin converts it to its constituent amino acids, and amino-acid derivatives ${ }^{70,99}$. The final form is known as natural moisture factor (NMF) and it can represent up to $10 \%$ of the corneocyte dry weight. The complex composition of the NMF mixture can explain the presence of numerous features of the spectrum recorded from the stratum corneum. The pattern of the Raman spectra presented in figure 6-I is consistent with data that can be found in the literature focusing on the study of the corneocyte maturation ${ }^{90}$. Moreover, the protein features are highlighted in the absence of the normally strong lipidic spectral features.

Figure 6-II shows a comparison between cluster 5 of dewaxed hand skin and the equivalent cluster for thigh skin with pure melanin. As described in section 3, both clusters (figure 6-IIA and 6-II-B) can be attributed to a combination of the basal and malpighian layer of the human skin, both rich in melanin. Again, the intensities of the spectra are exceptionally high and the spectra are dominated by the fluorescence spectrum of melanin. The spectra are similar to the corresponding spectra from the unprocessed tissue sections (Figure 2-II-A and 2-II-B). However, no lipidic peaks are observable and, notably, no differences between the spectra of cluster 5 of dewaxed hand and the equivalent thigh spectrum are apparent (figure 6-II-A and 6-II-B). The process of waxing and dewaxing therefore substantially reduces the lipidic content of the intermediate epithelial layers, such that intermediate epithelial layers from different anatomical sites such as hand and thigh cannot be distinguished from each other.

Figure 6-III presents a comparison between the KMCA spectra of cluster 2 of dewaxed hand dermis and the equivalent cluster for thigh (figures 6-III-A and 6-III-B) with pure collagen (figure 6-III-C). As is the case with the epidermis layers, no lipidic peaks are observed. In contrast to the spectra of dermal clusters of unprocessed hand and thigh (figure 2-I-A and 2-IB), the spectra look identical. The process of waxing and dewaxing appears to have removed 
all lipidic constituents, and therefore the dermis from different anatomical sites such as hand and thigh cannot be distinguished.

The Raman spectra of the stratrum corneum and dermis of the dewaxed skin sections from different anatomical regions and from different human cadavers are shown in (figure 3-I and 3-II). Remarkably, comparing the Raman spectra of dewaxed epidermis and dermis of human skin from three different cadavers, no significant differences can be found. As in the case of unprocessed sections, the results are representative of all 11 cadavers measured.

To confirm the depeletion of the lipidic content of the tissue, Figure 7 shows the high wavenumber regions of the spectra of dewaxed human thigh stratum corneum, intermediate epithelial layer and dermis. As for the unprocessed sections, the spectra were fitted with a series of Gaussian/Lorentzian bands, and the spectral positioning $\left( \pm 3 \mathrm{~cm}^{-1}\right)$, intensities $( \pm 10 \%)$ and assignments are listed in table 3.

Comparison of the relative intensities of the lipid peaks of unprocessed and processed tissue sections of hand and thigh in table 2 and table 3 confirms that the dewaxing procedure has significantly reduced the lipidic content and altered the tissue composition of the skin. Strikingly, however, the remaining biochemical structure of the skin layers is remarkably consistent across different cadavers and anatomical sites.

The lipidic content is the key to the permeability barrier function of skin and is of significant importance to the cosmetics industry and for transdermal drug delivery. Abnormalities in barrier function associated with lipid content are also associated with atopic dermatitis and other common cutaneous diseases ${ }^{100}$. UV radiation has been shown to effect the free fatty acid and triglyceride composition ${ }^{101}$ and decrease in lipid content with age is associated with increased susceptibility to exogenous insults, ${ }^{94}$. Therefore, a detailed knowledge of lipidic content, composition and structure is critical to many studies of skin function, malfunction 
and abnormality. Although archived tissue sample can serve as an important source for retrospective studies, this study demonstrates that, in their dewaxed form, no information related to their lipid content can be gleaned. Nevertheless, the study shows that the cellular content of the tissue and the protein extracellular matrix remain largely intact, and that the spectral profiles are enhanced by the removal of the lipidic content.

\section{Conclusions}

Raman spectroscopy and K-means cluster analysis successfully discriminates the layers of the unprococessed and dexwaxed skin from two different anatomical sites, hand and thigh. Kmeans cluster analysis further shows that distinct biochemcial regions within the skin tissue can be identified, corresponding to the top layer stratum corneum and the bottom layer dermis. However, the strong contibution from melanin fluoresecene prevents a clear discrimination between the stratum basale and stratum spinosum. In the unprocessed skin, the spectrum of the stratum corneum has strong contributions from the cellular components, the spectrum of the intermediate epithelial layer is strongly influenced by melanin while that of the dermis is dominated by collagen. In all cases, lipidic contibutions to the spectra are discernible, notably in the stratum corneum, which is relatively rich in lipidic content. The lipidic content can also be used to differentiate between anatomical sites. The process of tissue fixation, embedding and dewaxing has the effect of significantly reducing the lipidic content of all skin layers. This has the implication that antomically different tissue sections which may differ significantly in terms of fat content become indistinguishable, and it is no longer possible to study skin functions or abnormalities accociated with lipid content. However, the cellular and extracellular structures remain relatively intact and the spectral features are accentuated in the absence of lipidic contributions, and so processed archived tissue banks present a valuable resource for the retrospective study of skin diesase. 


\section{Acknowledgements}

This research was supported by the National Biophotonics and Imaging Platform (NBIP) Ireland funded under the Higher Education Authority PRTLI (Programme for Research in Third Level Institutions) Cycle 4, co-funded by the Irish Government and the European Union Structural Fund. 


\section{Figure legends:}
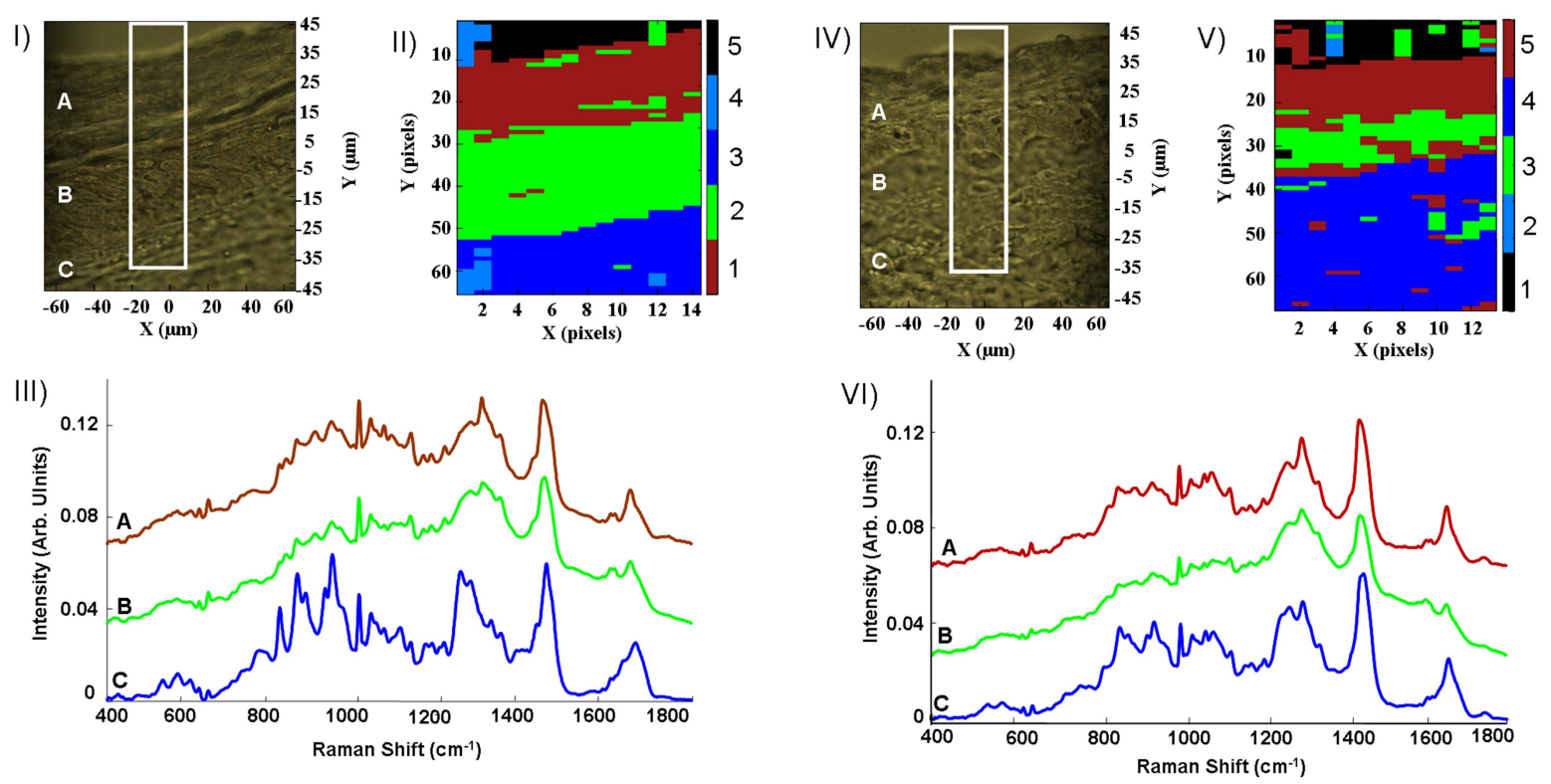

Figure 1: I) Optical image of unprocessed hand tissue section; II) K-means cluster analysis of Raman maps of unprocessed hand; III) KMCA mean Raman spectra of unprocessed hand illustrating the differentiation of the superficial stratum corneum (cluster $1=\mathrm{A}$ ), the intermediate epithelium (cluster $2=\mathrm{B}$ ), and the dermis (cluster $3=\mathrm{C}$ ); IV) Optical image of unprocessed thigh tissue section; V) K-means cluster analysis of Raman map of unprocessed thigh; VI) KMCA mean Raman spectra of unprocessed thigh, illustrating the differentiation of the superficial stratum corneum (cluster $5=\mathrm{A}$ ), the underlying epithelium (cluster $3=\mathrm{B}$ ), and the dermis (cluster $4=\mathrm{C}$ ). 


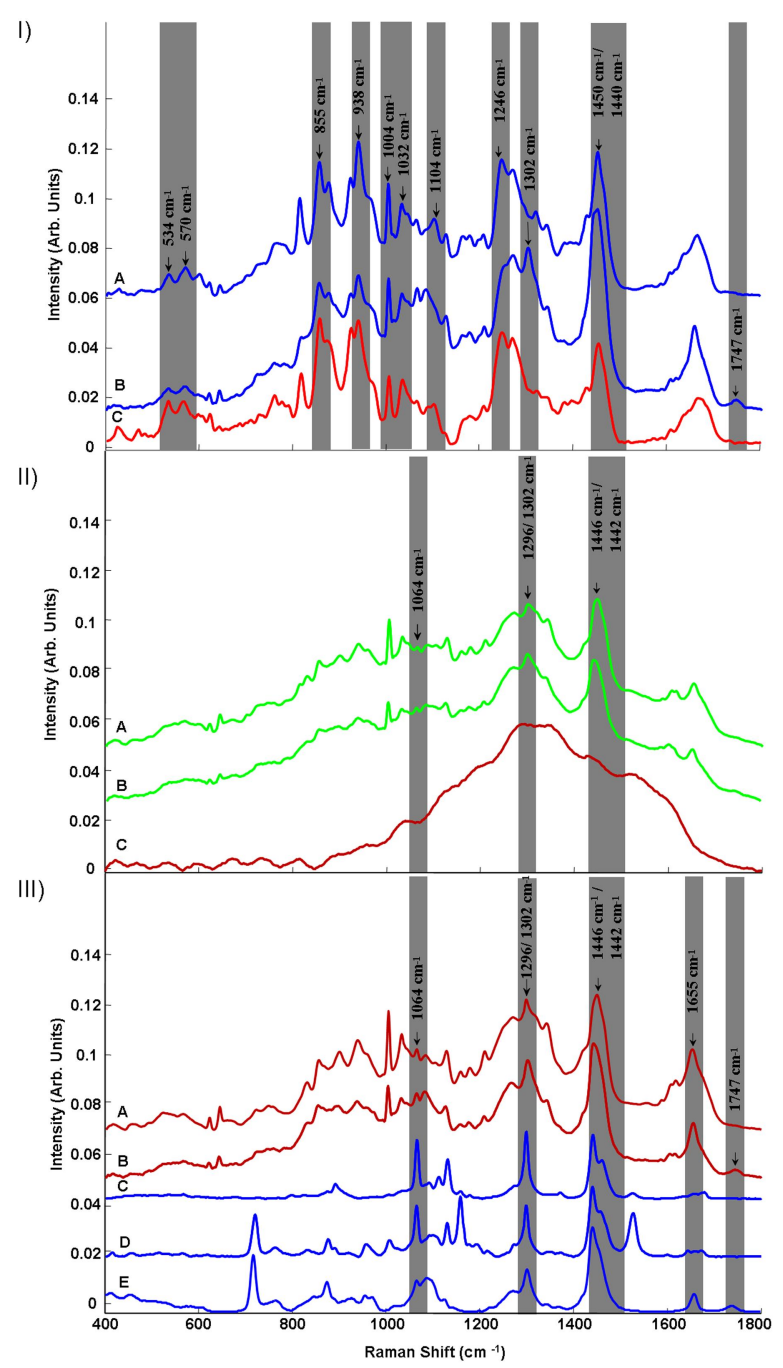

Figure 2: I) KMCA mean spectra of unprocessed hand skin dermis cluster (cluster 3) (A), unprocessed thigh skin dermis cluster (cluster 4) (B) and spectrum of pure collagen (C); II) KMCA mean spectra of the intermediate epithelial layer cluster (cluster 2) of unprocessed frozen hand skin (A), the intermediate epithelial layer cluster (cluster 3) of unprocessed thigh skin (B) and spectrum of pure melanin (C); III) KMCA mean spectra of the stratum corneum cluster (cluster 1) of unprocessed hand (A), the stratum corneum cluster (cluster 5) of unprocessed thigh (B), spectra of Ceramide (C), Sphingomyelin (D) and L- $\alpha$ Phosphatidylcholine (E). 


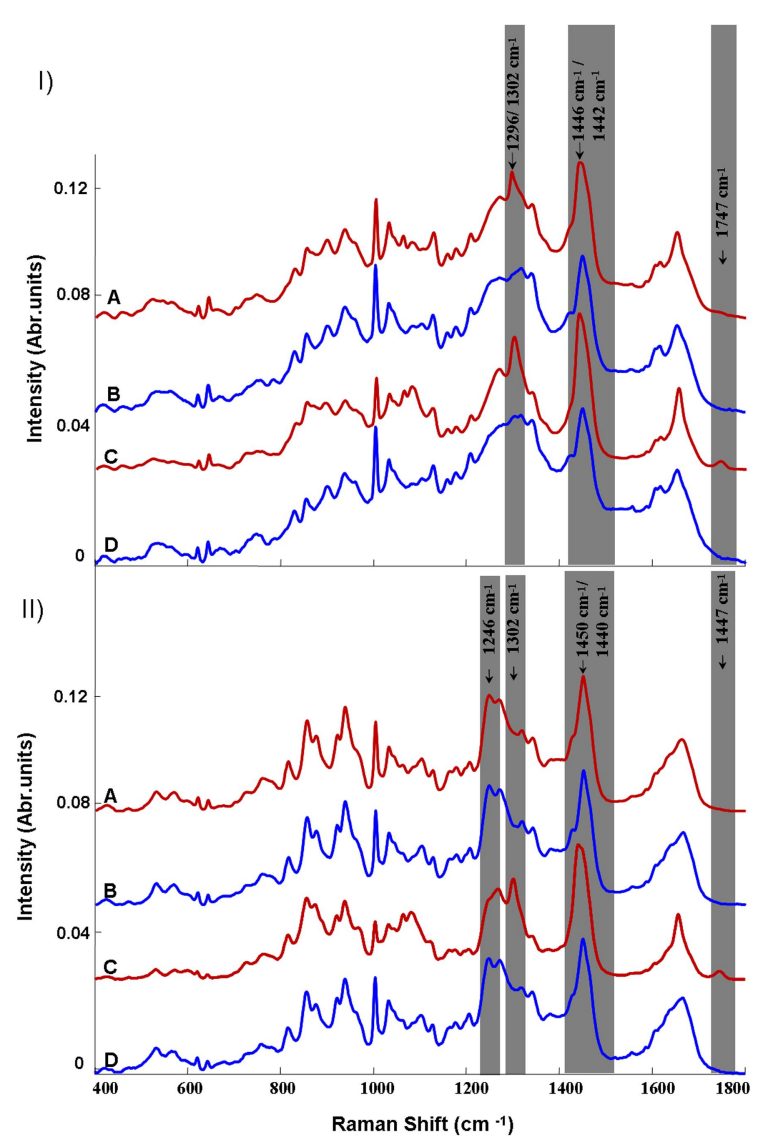

Figure 3: I) A: Average Raman spectrum of the unprocessed hand SC; B: Average Raman spectrum of the dewaxed hand SC ; C: Average Raman spectrum of the unprocessed thigh SC; D: Average Raman spectrum of the dewaxed thigh SC. II) A: Average Raman spectrum of the unprocessed hand dermis; B: Average Raman spectrum of the dewaxed hand dermis ; C: Average Raman spectrum of the unprocessed thigh dermis; D: Average Raman spectrum of the dewaxed thigh dermis. 


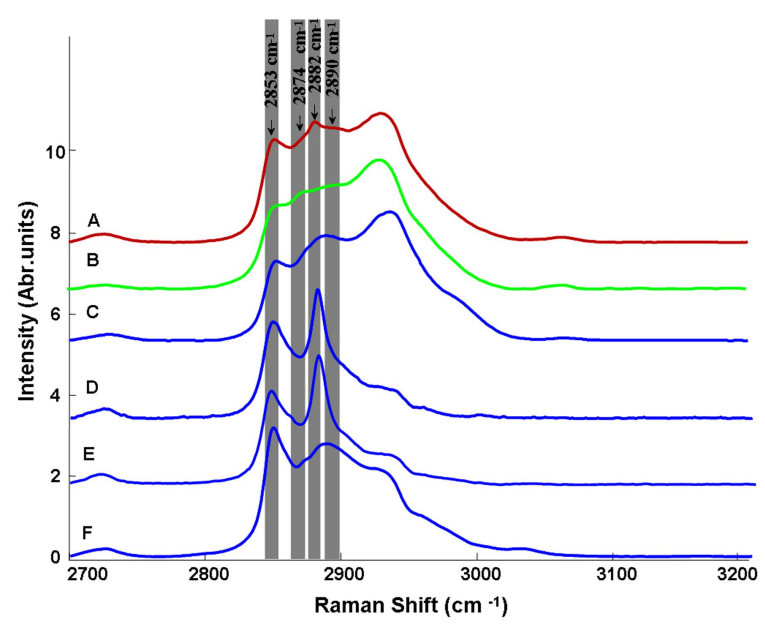

Figure 4: Average Raman spectra of high wavenumber region of unprocessed thigh stratum corneum (A), unprocessed intermediate epithelial layer (B), unprocessed dermis (C), ceramide (D), sphingomyline (E) and L- $\alpha$ - phosphatidylcholine (F).
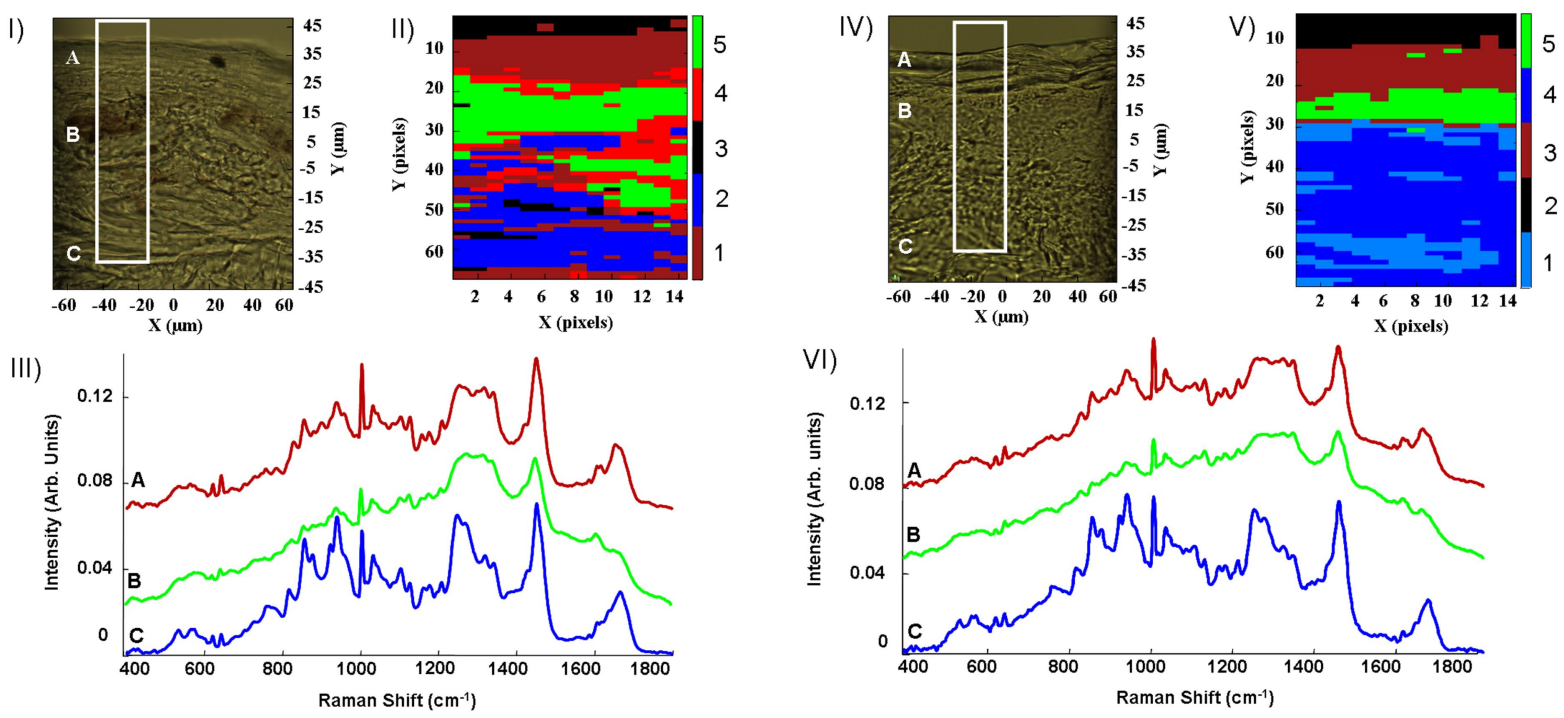

Figure 5: I) Optical image of dewaxed hand tissue section; II) KMCA of Raman spectral ; map; III) KMCA mean Raman spectra of processed hand illustrating the differentiation of the superficial stratum corneum (cluster $1=\mathrm{A}$ ), the intermediate epithelium (cluster $5=\mathrm{B}$ ), and the dermis (cluster $2=\mathrm{C}$ ); IV) Optical image of processed thigh tissue section; V) KMCA of Raman map; VI) KMCA mean Raman spectra of processed thigh, illustrating the 
differentiation of the superficial stratum corneum (cluster $3=\mathrm{A}$ ), the intermediate epithelium (cluster $5=\mathrm{B})$, and the dermis (cluster $4=\mathrm{C}$ ).

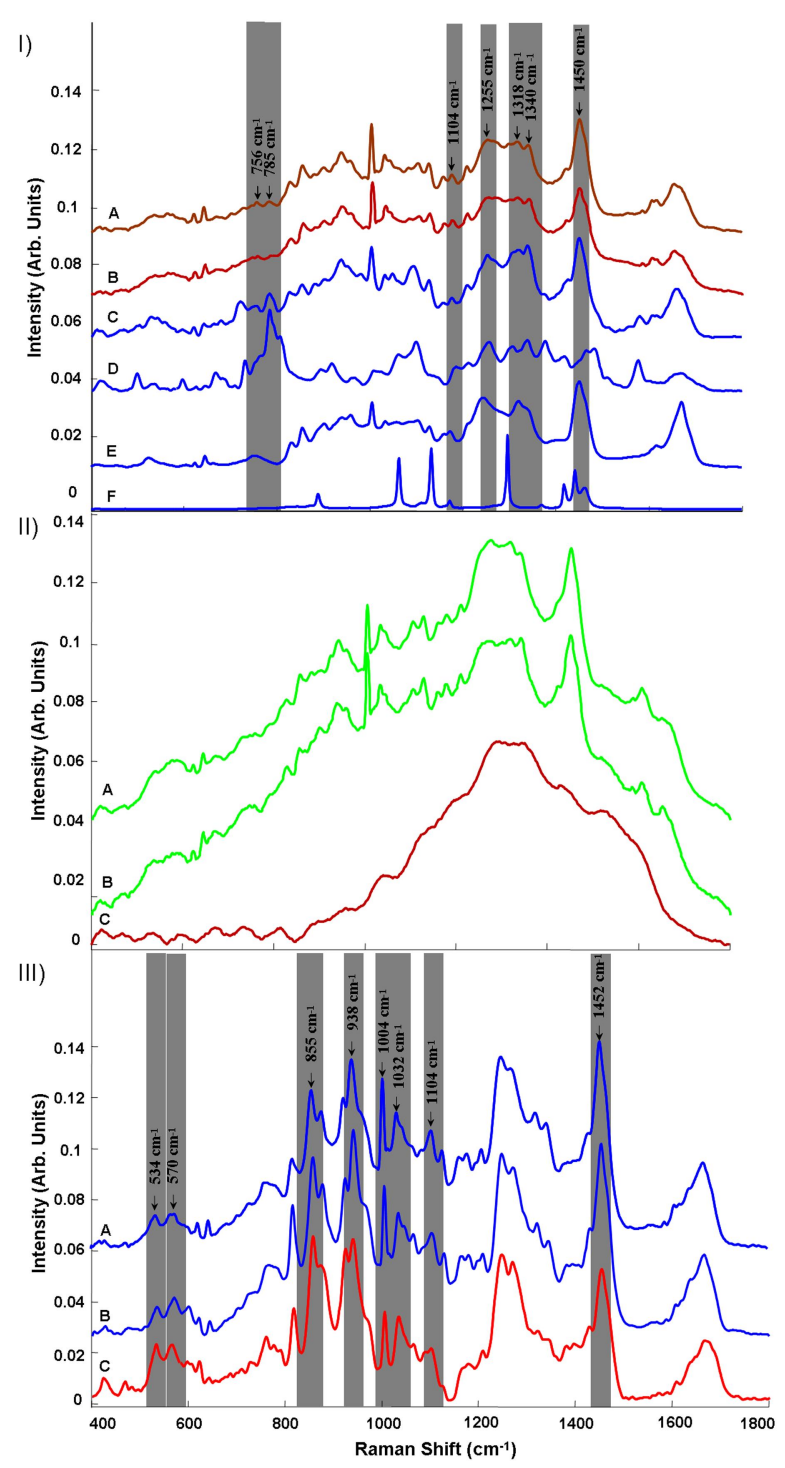

Figure 6: I) KMCA mean spectra of cluster 1 from dewaxed skin hand (A) cluster 3 from dewaxed thigh (B), Raman spectra of HaCaT cells (C), DNA (D), Histone (E) and pure paraffin wax (F).II) KMCA mean Raman spectra of cluster 5 from dewaxed skin hand (A), cluster 5 from dewaxed thigh (B) and spectrum of pure melanin (C). III) KMCA mean Raman spectra of cluster 2 dewaxed skin hand (A) cluster 4 dewaxed thigh (B) pure collagen (C). 


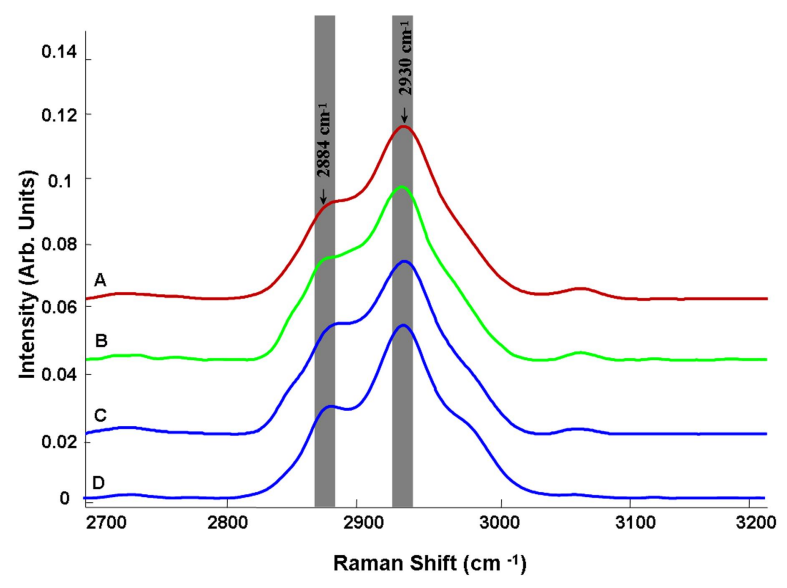

Figure 7: Average Raman spectra of the high wavenumber region of dewaxed human thigh section from stratum corneum (A), intermediate epithelial layer (B), dermis (C) and pure collagen (D). 
Table 1: Human cadavers. Spectral profiling of hand and thigh sections, unprocessed and processed, of the samples indicated by shading are presented in detail.

\begin{tabular}{|c|c|c|c|}
\hline Identification No. & Sex & Age & Cause of death \\
\hline Sample n ${ }^{0} 1$ & Female & 82 & Pancreatic Malignancy \\
\hline Sample n⿳2 2 & Female & 98 & Bronchopneumonia \\
\hline Sample n⿳3 & Female & 88 & Myocardial infarction \\
\hline Sample n⿳0 4 & Female & 88 & Sepsis (SBO) \\
\hline Sample n 5 & Female & 89 & Cerebrovascular Accident \\
\hline Sample n 6 & Female & 78 & Bronchopneumonia \\
\hline Sample n⿳07 & Female & 93 & Sepsis (UTI) \\
\hline Sample no & Male & 77 & COPD \\
\hline Sample n9 & Male & 89 & Cerebrovascular Accident \\
\hline Sample $\mathbf{n}^{0} \mathbf{1 0}$ & Male & 81 & Myocardial Infarction \\
\hline Sample n⿳1口 11 & Male & 73 & Motor Neuron Disease \\
\hline
\end{tabular}


Table 2: Fitted peak positions, relative intensities and assignments for the high wavenumber region of average Raman spectra of unprocessed skin sections.

\begin{tabular}{|c|c|c|c|c|c|}
\hline \multicolumn{2}{|c|}{ Peak Position $\left(\mathrm{cm}^{-1}\right)$} & \multirow{2}{*}{$\begin{array}{c}\begin{array}{c}\text { Stratum } \\
\text { corneum }\end{array} \\
0.12\end{array}$} & \multirow{2}{*}{$\begin{array}{c}\text { Dermis } \\
0.08\end{array}$} & \multirow{2}{*}{$\begin{array}{c}\begin{array}{c}\text { Intermediate } \\
\text { Epithelium }\end{array} \\
0.07\end{array}$} & \multirow{3}{*}{$\begin{array}{l}\text { Assignment } \\
\begin{array}{c}\text { CH stretching } \\
\text { (lipid) }\end{array}\end{array}$} \\
\hline Thigh & 2730 & & & & \\
\hline Hand & & 0.06 & 0.05 & 0.02 & \\
\hline Thigh & 2850 & 0.73 & 0.56 & 0.80 & $\begin{array}{l}\mathrm{CH}_{2} \text { stretching } \\
\text { (lipid) }\end{array}$ \\
\hline Hand & & 0.65 & 0.24 & 0.65 & \\
\hline Thigh & 2863 & 0.67 & 0.43 & 0.73 & $\begin{array}{c}\mathrm{CH}_{3} \text { stretching } \\
\text { (protein) }\end{array}$ \\
\hline Hand & & 0.70 & 0.45 & 0.59 & \\
\hline Thigh & 2880 & 0.42 & 0.46 & 0.03 & $\begin{array}{c}\mathrm{CH}_{2} \text { stretching } \\
\text { (lipid) }\end{array}$ \\
\hline Hand & & 0.13 & 0.08 & 0.002 & \\
\hline Thigh & 2905 & 1.03 & 0.93 & 1.16 & $\begin{array}{l}\text { CH stretching } \\
\text { (protein) }\end{array}$ \\
\hline Hand & & 0.80 & 0.67 & 0.94 & \\
\hline Thigh & 2933 & 1 & 1 & 1 & $\begin{array}{c}\mathrm{CH}_{3} \text { stretching } \\
\text { (protein) }\end{array}$ \\
\hline Hand & & 1 & 1 & 1 & \\
\hline Thigh & 2968 & 0.59 & 0.50 & 0.82 & $\begin{array}{c}\mathrm{CH}_{3} \text { stretching } \\
\text { (protein) }\end{array}$ \\
\hline Hand & & 0.50 & 0.53 & 0.64 & \\
\hline Thigh & 3065 & 0.05 & 0.03 & 0.07 & $\begin{array}{c}\text { Amide B } \\
\text { (Protein) } \\
\text { (CNH bend) }\end{array}$ \\
\hline Hand & & 0.05 & 0.06 & 0.07 & \\
\hline
\end{tabular}


Table 3: Fitted peak positions, intensities and assignments for high wavenumber region of average Raman spectra of dewaxed thigh skin section.

\begin{tabular}{|c|c|c|c|c|}
\hline Peak Position $\left.\mathbf{( c m}^{-1}\right)$ & Stratum & Dermis & Intermediate & Assignment \\
& corneum & & Epithelium & \\
\hline 2730 & 0.05 & 0.04 & 0.04 & $\mathrm{CH}$ stretching (lipid) \\
\hline 2850 & 0.17 & 0.18 & 0.35 & $\mathrm{CH}_{2}$ stretching (lipid) \\
\hline 2863 & 0.59 & 0.28 & 0.63 & $\mathrm{CH}_{3}$ stretching (protein) \\
\hline 2880 & 0.02 & 0.16 & 0.09 & $\mathrm{CH}_{2}$ stretching (lipid) \\
\hline 2905 & 0.87 & 0.57 & 0.93 & $\mathrm{CH}^{\text {stretching (protein) }}$ \\
\hline 2933 & 1 & 1 & 1 & $\mathrm{CH}_{3}$ stretching (protein) \\
\hline 2968 & 0.69 & 0.49 & 0.79 & $\mathrm{CH}_{3}$ stretching (protein) \\
\hline 3065 & 0.10 & 0.02 & 0.07 & Amide B (Protein) $_{\text {(CNH bend) }}$ \\
\hline & & & & \\
\hline
\end{tabular}




\section{Reference}

1. Meade AD, Byrne HJ, Lyng FM, Mutat Res, 2010, 704, 108-114.

2. Knief P, Clarke C, Herzog E, Davoren M, Lyng FM, Meade AD, Byrne HJ, Analyst, 2009, 134, 1182-1191.

3. Ling J, Weitman SD, Miller MA, Moore RV, Bovik AC, Appl Opt, 2002, 41, 6006-6017.

4. Sebiskveradze D, Vrabie V, Gobinet C, Durlach A, Bernard P, Ly E, Manfait M, Jeannesson P, Piot O, Lab Invest, 2011, 91, 799-811.

5. Wolthuis R, Travo A, Nicolet C, Neuville A, Gaub MP, Guenot D, Ly E, Manfait M, Jeannesson P, Piot O, Anal Chem, 2008, 80, 8461-8469.

6. Nawaz H, Bonnier F, Knief P, Howe O, Lyng FM, Meade AD, Byrne HJ, Analyst, 2010, 135, 3070-3076.

7. Draux F, Jeannesson P, Gobinet C, Sule-Suso J, Pijanka J, Sandt C, Dumas P, Manfait M, Sockalingum GD, Anal Bioanal Chem, 2009, 395, 2293-2301.

8. Bonnier F, Knief P, Lim B, Meade AD, Dorney J, Bhattacharya K, Lyng FM, Byrne HJ, Analyst, 2010, 135, 3169-3177.

9. Miljkovic M, Chernenko T, Romeo MJ, Bird B, Matthaus C, Diem M, Analyst, 2010, 135, 2002-2013.

10. Mahadevan-Jansen A, Mitchell MF, Ramanujam N, Malpica A, Thomsen S, Utzinger U, Richards-Kortum R, Photochem Photobiol, 1998, 68, 123-132.

11. Utzinger U, Brewer M, Silva E, Gershenson D, Blast RC, Jr., Follen M, Richards-Kortum R, Lasers Surg Med, 2001, 28, 56-66.

12. Huang Z, McWilliams A, Lui H, McLean DI, Lam S, Zeng H, Int J Cancer, 2003, 107, 1047 1052.

13. Kaminaka S, Yamazaki H, Ito T, Kohda E, Hamaguchi H, Journal of Raman Spectroscopy, 2001, Volume 32, 139-141.

14. Mizuno A, Kitajima H, Kawauchi K, Muraishi S, Ozaki Y, Journal of Raman Spectroscopy 1994, 25, 25-29.

15. Boere IA, Robinson DJ, de Bruijn HS, van den Boogert J, Tilanus HW, Sterenborg HJ, de Bruin RW, Photochem Photobiol, 2003, 78, 271-277.

16. Kendall C, Stone N, Shepherd N, Geboes K, Warren B, Bennett R, Barr H, J Pathol, 2003, 200, 602-609.

17. Boere IA, Schut TCB, van den Boogert J, de Bruin RWF, Puppels GJ, Vibrational Spectroscopy, 2003, 32, 47-55.

18. Molckovsky A, Song LM, Shim MG, Marcon NE, Wilson BC, Gastrointest Endosc, 2003, 57, 396-402.

19. Krafft C, Codrich D, Pelizzo G, Sergo V, Journal of Biophotonics, 2008, 1, 154-169.

20. Crow P, Stone N, Kendall CA, Uff JS, Farmer JA, Barr H, Wright MP, Br J Cancer, 2003, 89, 106-108.

21. Lau DP, Huang Z, Lui H, Man CS, Berean K, Morrison MD, Zeng H, Lasers Surg Med, 2003, 32, 210-214.

22. Lau DP, Huang Z, Lui H, Anderson DW, Berean K, Morrison MD, Shen L, Zeng H, Lasers Surg Med, 2005, 37, 192-200.

23. Krishna CM, Sockalingum GD, Kurien J, Rao L, Venteo L, Pluot M, Manfait M, Kartha VB, Appl Spectrosc, 2004, 58, 1128-1135.

24. Frank CJ, McCreery RL, Redd DC, Anal Chem, 1995, 67, 777-783.

25. Shafer-Peltier KE, Haka AS, Motz JT, Fitzmaurice M, Dasari RR, Feld MS, J Cell Biochem Suppl, 2002, 39, 125-137.

26. Shafer-Peltier KE, Haka AS, Fitzmaurice M, Crowe J, Myles J, Dasari RR, Feld MS, Journal of Raman Spectroscopy, 2002, 33, 552-563.

27. Abramczyk H, Brozek-Pluska B, Surmacki J, Jablonska J, Kordek R, Journal of Molecular Liquids, 2011, 164, 123-131. 
28. Hawi SR, Campbell WB, Kajdacsy-Balla A, Murphy R, Adar F, Nithipatikom K, Cancer Lett, 1996, 110, 35-40.

29. Ly E, Piot O, Durlach A, Bernard P, Manfait M, Analyst, 2009, 134, 1208-1214.

30. Ly E, Piot O, Wolthuis R, Durlach A, Bernard P, Manfait M, Analyst, 2008, 133, 197-205.

31. Caspers PJ, Lucassen GW, Carter EA, Bruining HA, Puppels GJ, J Invest Dermatol, 2001, 116, 434-442.

32. Nijssen A, Bakker Schut TC, Heule F, Caspers PJ, Hayes DP, Neumann MH, Puppels GJ, J Invest Dermatol, 2002, 119, 64-69.

33. Ly E, Piot O, Durlach A, Bernard P, Manfait M, Applied Spectroscopy, 2008, 62, 1088-1094.

34. Wegenera M, Neubert R, Rettiga W, Wartewig S, International Journal of Pharmaceutics, 1996, 128, 203213.

35. Tfayli A, Guillard E, Manfait M, Baillet-Guffroy A, Anal Bioanal Chem, 2010, 397, 12811296.

36. Bancroft JD, Gamble M. 2002. Theory and Practice of Histological Techniques. London: Churchill Livingstone.

37. Drury R, Wallington E. 1980. Carleton's Histological technique. Oxford: Oxford University Press.

38. Faolain EO, Hunter MB, Byrne JM, Kelehan P, Lambkin HA, Byrne HJ, Lyng FM, J Histochem Cytochem, 2005, 53, 121-129.

39. Tfayli A, Gobinet C, Vrabie V, Huez R, Manfait M, Piot O, Appl Spectrosc, 2009, 63, 564570.

40. Draux F, Gobinet C, Sule-Suso J, Trussardi A, Manfait M, Jeannesson P, Sockalingum GD, Anal Bioanal Chem, 2010, 397, 2727-2737.

41. Mariani MM, Lampen P, Popp J, Wood BR, Deckert V, Analyst, 2009, 134, 1154-1161.

42. Meade A, Clarke C, Draux F, Sockalingum G, Manfait M, Lyng F, Byrne H, Analytical and Bioanalytical Chemistry, 2010, 396, 1781-1791.

43. Boukamp P, Petrussevska RT, Breitkreutz D, Hornung J, Markham A, Fusenig NE, J Cell Biol, 1988, 106, 761-771.

44. Ockenfels HM, Nussbaum G, Schultewolter T, Burger PM, Goos M, Arch Dermatol Res, 1995, 287, 304-309.

45. Choquette SJ, Etz ES, Hurst WS, Blackburn DH, Leigh SD, Appl Spectrosc, 2007, 61, 117 129.

46. Bonnier F, Mehmood A, Knief P, Meade AD, Hornebeck W, Lambkin H, Flynn K, McDonagh V, Healy C, Lee TC, Lyng FM, Byrne HJ, Journal of Raman Spectroscopy, 2011, 42, 888896.

47. Koljenovic S, Schut TCB, van Meerbeeck JP, Maat A, Burgers SA, Zondervan PE, Kros JM, Puppels GJ, Journal of Biomedical Optics, 2004, 9, 1187-1197.

48. Caspers PJ, Lucassen GW, Wolthuis R, Bruining HA, Puppels GJ, Biospectroscopy, 1998, 4, S31-S39.

49. Tfayli A, Piot O, Durlach A, Bernard P, Manfait M, Biochim Biophys Acta, 2005, 1724, 262 -

269.

50. Silver FH, Freeman JW, DeVore D, Skin Res Technol, 2001, 7, 18-23.

51. Frushour BG, Koenig JL, Biopolymers, 1975, 14, 379-391.

52. De Gelder J, Scheldeman P, Leus K, Heyndrickx M, Vandenabeele P, Moens L, De Vos P, Anal Bioanal Chem, 2007, 389, 2143-2151.

53. Jess PR, Smith DD, Mazilu M, Dholakia K, Riches AC, Herrington CS, Int J Cancer, 2007, 121, 2723-2728.

54. Notingher I, Hench LL, Expert Rev Med Devices, 2006, 3, 215-234.

55. Notingher I, Verrier S, Haque S, Polak JM, Hench LL, Biopolymers, 2003, 72, 230-240.

56. Tfayli A, Piot O, Draux F, Pitre F, Manfait M, Biopolymers, 2007, 87, 261-274.

57. Kollias N, T Clin. Dermatol., 1995, 13, 361-367.

58. Odland GF.in Physiology, Biochemistry and molecular Biology of the skin, Goldsmith LA, Oxford University Press, New York, 1991, 
59. Jablonski NG, Annu. Rev. Anthropol., 2004, 33, 585-623.

60. Huang Z, Lui H, Chen XK, Alajlan A, McLean DI, Zeng H, J Biomed Opt, 2004, 9, 11981205.

61. Williams AC, Barry BW, Edwards HGM, Farwell DW, Pharmaceutical Research, 1993, 10, 1642-1647.

62. Williams AC, Edwards HGM, Barry BW, International Journal of Pharmaceutics, 1992, 81, R11-R14.

63. Barry BW, Edwards HGM, Williams AC, Journal of Raman Spectroscopy, 1992, 23, 641645.

64. Edwards HGM, Farwell DW, Williams AC, Barry BW, Rull F, Journal of the Chemical Society-Faraday Transactions, 1995, 91, 3883-3887.

65. Anigbogu ANC, Williams AC, Barry BW, Edwards HGM, International Journal of Pharmaceutics, 1995, 125, 265-282.

66. Potts RO, Guzek DB, Harris RR, McKie JE, Arch Dermatol Res, 1985, 277, 489-495.

67. Plasencia I, Norlen L, Bagatolli LA, Biophys J, 2007, 93, 3142-3155.

68. Lampe MA, Burlingame AL, Whitney J, Williams ML, Brown BE, Roitman E, Elias PM, J Lipid Res, 1983, 24, 120-130.

69. Melnik BC, Hollmann J, Erler E, Verhoeven B, Plewig G, J Invest Dermatol, 1989, 92, 231234.

70. Harding CR, Watkinson A, Rawlings AV, Scott IR, Int J Cosmet Sci, 2000, 22, 21-52.

71. Darvin ME, Fluhr JW, Caspers P, van der Pool A, Richter H, Patzelt A, Sterry W, Lademann J, Exp Dermatol, 2009, 18, 1060-1063.

72. Krinsky NI, Nutrition, 2001, 17, 815-817.

73. Lademann J, Schanzer S, Meinke M, Sterry W, Darvin ME, Skin Pharmacol Physiol, 2011, 24, 238-244.

74. Hulsbergen Henning JP, Beerens EG, van der Leun JC, Arch Dermatol Res, 1977, 258, 25-32.

75. Corcuff P, Leveque JL, Dermatology, 1993, 186, 50-54.

76. Kligman AM, The Epidermis. New York: Academic Press, 1964, 407-408.

77. Whitton JT, Everall JD, British Journal of Dermatology, 1973, 89, 467-476.

78. Holbrook KA, Odland GF, J Invest Dermatol, 1974, 62, 415-422.

79. Huzaira M, Rius F, Rajadhyaksha M, Anderson RR, Gonzalez S, Journal of Investigative Dermatology, 2001, 116, 846-852.

80. Robertson K, Rees JL, Acta Derm Venereol, 2010, 90, 368-373.

81. Sandby-Moller J, Poulsen T, Wulf HC, Acta Derm Venereol, 2003, 83, 410-413.

82. Gniadecka M, Faurskov Nielsen O, Christensen DH, Wulf HC, J Invest Dermatol, 1998, 110, 393-398.

83. Gniadecka M, Nielsen OF, Wessel S, Heidenheim M, Christensen DH, Wulf HC, J Invest Dermatol, 1998, 111, 1129-1133.

84. Michaels AS, Chandrasekaran SK, Shaw JE, Aiche Journal, 1975, 21, 985-996.

85. Grayson S, Elias PM, Journal of Investigative Dermatology, 1982, 78, 128-135.

86. Wertz PW, Downing DT, Science, 1982, 217, 1261-1262.

87. Wertz PW, Advanced Drug Delivery Reviews, 1996, 18, 283-294.

88. Wertz PW, van den Bergh B, Chemistry and Physics of Lipids, 1998, 91, 85-96.

89. Jungersted JM, Hellgren LI, Jemec GBE, Agner T, Contact Dermatitis, 2008, 58, 255-262.

90. Zhang G, Moore DJ, Flach CR, Mendelsohn R, Anal Bioanal Chem, 2007, 387, 1591-1599.

91. Wertz PW, Downing DT.in Physiology, Biochemistry and molecular biology of the skin, Goldsmith LA, Oxford University Press, New York, 1991,205-236

92. Downing DT, J Lipid Res, 1992, 33, 301-313.

93. Mizutani Y, Mitsutake S, Tsuji K, Kihara A, Igarashi Y, Biochimie, 2009, 91, 784-790.

94. Ghadially R, Brown BE, Sequeiramartin SM, Feingold KR, Elias PM, Journal of Clinical Investigation, 1995, 95, 2281-2290. 
95. Guillard E, Tfayli A, Manfait M, Baillet-Guffroy A, Anal Bioanal Chem, 2011, 399, 12011213.

96. Merle C, Laugel C, Baillet-Guffroy A, Photochem Photobiol, 2010, 86, 553-562.

97. Tfayli A, Guillard E, Manfait M, Baillet-Guffroy A, Eur J Dermatol, 2012, 22, 36-41.

98. Gobinet C, Vrabie V, Tfayli A, Piot O, Huez R, Manfait M, Conf Proc IEEE Eng Med Biol Soc, 2007, 2007, 6208-6211.

99. Scott IR, Harding CR, Dev Biol, 1986, 115, 84-92.

100. Feingold KR, Journal of Lipid Research, 2007, 48, 2529-2530.

101. Kim EJ, Jin XJ, Kim YK, Oh IK, Kim JE, Park CH, Chung JH, J Dermatol Sci, 2010, 57, 1926. 